Complutense Journal of English Studies

ISSN: 2386-3935

http://dx.doi.org/10.5209/CJES.56533

\title{
The invisible reality: English teaching materials and the formation of gender and sexually oriented stereotypes (with a focus on primary education $)^{1}$
}

\author{
Silvia Pellicer Ortín²; Alicia Asín Abad ${ }^{3}$
}

\begin{abstract}
Gender stereotypes, understood as those structured sets of beliefs about personal attributes of women and men, have a great influence over self-perspective and the social interaction and organisation. However, their effects are sometimes invisible, and a great effort should be made to develop awareness of their influence in the population. Our main claim is that School has an essential role to teach gender and sexual equality through the curricula, using teaching materials that are free of these stereotypes. The main aim of this study is to examine the presence of gender and sexually oriented stereotypes in various English teaching materials within the context of the Spanish Primary School, focusing on its last stage. This research carries out a qualitative and quantitative analysis of three English textbooks together with the students' and teachers' perceptions of gender stereotypes. The analysis is done thanks to the review of key concepts, such as gender awareness and sexual identity, as well as the presentation of various examination tools that have allowed us to evaluate the sexist content in the textbooks selected and offer some guidelines to avoid them in the English classroom.
\end{abstract}

Keywords: gender and sexually oriented stereotypes, gender awareness, EFL teaching, English textbooks.

\section{[es] La realidad invisible: materiales didácticos para la enseñanza de inglés y la creación de estereotipos de sexo y género (enfocado en la etapa de educación primaria)}

Resumen. Los estereotipos de género, entendidos como el conjunto de creencias sobre los atributos personales de mujeres y hombres, ejercen una influencia importante sobre la autoperspectiva y la interacción y organización en nuestra sociedad. Sin embargo, sus efectos son a veces invisibles, y desarrollar una conciencia sobre su influencia en la población requiere un gran esfuerzo. Nuestro argumento primordial consiste en que la Escuela tiene un papel esencial a la hora de enseñar sobre la igualdad de género y sexo a través del currículo, usando materiales didácticos que estén libres de este tipo de estereotipos. Así pues, el principal objetivo de este estudio es examinar la presencia de estereotipos de sexo y género en varios materiales didácticos para la enseñanza de inglés en el contexto de la educación primaria española, centrándonos en su última etapa. Nuestra investigación se ha llevado a cabo mediante el análisis cualitativo y cuantitativo de tres libros de texto para la enseñanza del inglés como lengua extranjera junto con el estudio de las percepciones sobre los estereotipos de

1 The research carried out for the writing of this article has been made possible with the support of the project financed by the Spanish Ministry of Economy, Industry and Competitiveness (MINECO) (code FFI201784258-P), both in collaboration with the European Regional Development Fund (DGI/ERDF); the University of Zaragoza and Ibercaja (JIUZ-2017-HUM-02); and the Government of Aragón (H03_17R).

2 Departamento de Filología Inglesa y Alemana, Facultad de Educación, Universidad de Zaragoza, spellice@ unizar.es.

3 Primary School teacher, alicia.a.abad@gmail.com. 
género de alumnos y profesores. Para realizar este análisis hemos revisado conceptos clave, tales como la conciencia de género y la identidad sexual. Igualmente, hemos creado diferentes herramientas para evaluar el contenido sexista en los materiales elegidos y así ofrecer una serie de pautas que eviten la presencia de estos estereotipos en el aula de inglés en educación primaria.

Palabras clave: estereotipos de sexo y género, conciencia de género, enseñanza de inglés como lengua extranjera, libros de texto para la enseñanza de inglés.

Contents. 1. Introduction. 2. A feminist approach to the EFL context. 2.1. Defining gender and gender stereotypes. 2.2. The origin of gender stereotypes and the process of socialisation. 2.3. SCHOOL and gender stereotypes. 2.4. Language teaching approaches. 3. Methodology. 3.1. Surveys. 3.2. Collecting data and analysis of the results of the surveys. 3.3. Design of the checklist for the analysis of the textbooks. 4. Results and discussion. 4.1. Teachers' survey results. 4.2. Analysis of the textbooks. 4.3. Clothes analysis. 4.4. Students' survey results. 5. Conclusion.

How to cite this article: Pellicir Ortín, S.; Asín Abad, A. (2018) The invisible reality: English teaching materials and the formation of gender and sexually oriented stereotypes (with a focus on primary education), in Complutense Journal of English Studies 26, 165-191.

\section{Introduction}

Nowadays, most of us would agree that gender equality is a Universal Human Right; following, for instance, Secretary-General of the United Nations Ban Kin-Moon's definition as the socio-political attempt at "addressing structural barriers, the right of women and girls to govern their sexual and reproductive health, ending with violence against women and equal participation in society" (2016: 19). In a similar vein, we could also concur that the persistent discrimination on the grounds of sexual orientation and gender, which can still be identified in many places of our contemporary world, could be considered as an assault against these Human Rights ${ }^{4}$. Drawing on this, school, understood as the first socialising agent in children's life, together with their family contexts, should offer alternative gender roles and identities as well as promote this pertinent defence of Human Rights. Further, students in the present globalised world need to be offered a critical view of those existing gender stereotypes, roles and prejudices deeply rooted in our societies if they are expected to grow up as citizens who are free of gender-biased attitudes and beliefs.

In keeping with this, the main research question posed by this study is whether or not the teaching materials implemented in present-day classrooms contain, and consequently might promote gender and sexually oriented stereotypes. The importance of examining this topic draws on the idea that School transmits values and models that are reproduced by the students at different levels, as may be inferred in the teachers' attitudes, the students' interactions and the values contained in the teaching materials. Therefore, if we want to achieve equality in our societies in general and in the School in particular, one necessary measure should consist of carrying out a broad revision of the teaching materials used in our classrooms (Sunderland 1992). Notably, as will be further explained, an examination of textbooks is deemed as necessary because they are the main materials on which teachers base the content of their lessons and, on many occasions, the methodology of their teaching practice.

4 See Article 2 developed in the Universal Declaration of Human Rights (2016). 
In the case of the country that will be the object of our study, Spain, the need of this analysis is also justified by the Spanish curriculum, which underlines the role of the educational institutions in achieving an egalitarian society, being one of its general goals the development of students' critical awareness against violence, prejudices and gender stereotypes (see Real Decreto 126/2014: 19354). In this regard, our research hypothesis also relies on the fact that the English classroom, following a communicative approach, may be an ideal context to teach equality and to overcome gender stereotypes because, according to Lyons and Kashima, the reproduction of the values of a given culture takes place during the process of communication (2001: 372). In addition to this, Dai (2011) and Sowden (2007) recognise the interdependent relationship between language and culture and the increasing importance of teaching culture in English lessons. Considering these notions, the main objectives of this study could be stated as follows: i) to study some of the teachers' assumptions about the influence of teaching materials in the formation of stereotypes and their previous training about gender and sexually oriented stereotypes (with a focus on the last year of Primary Education); ii) to analyse the most frequent English textbooks that are used in a particular Spanish region, Aragón, according to a rigorous set of criteria; iii) to offer some general guidelines to those teachers trying to work on the different English communicative skills from a social and egalitarian perspective; iv) to analyse if students have internalised gender schema and to what extent school has influenced this process; and v) to demonstrate that teaching materials in our educative system in general, and in the English classroom in this case, are a decisive factor to consider when addressing the children's formation of gender stereotypes.

\section{A feminist approach to the EFL context}

This study draws on the initial premise that to achieve gender equality through our educative institutions it is essential to base this social change on some feminist principles, because feminism should be understood as "the belief that women and men are equal and should have equal rights. Thus, all feminist seek to end women's subordination" (Basow 1992: 329). The present situation of feminist thinking is difficult to define from a single approach because the third-feminist wave and Post-feminism, as well as other approaches such as transnational and intersectional feminism, coexist in our current globalised world. However, what seems to be clear is that the feminist movements are still fighting for achieving gender equality.

Therefore, this study will mainly rely on those authors who have formulated theories that can be encompassed in what has come to be defined as Post-feminism: a movement derived from the psychoanalytical school of thought and the postmodernist view of the world, and which tried to challenge and redefine some concepts that had been analysed by previous feminist theories, such as the intersection of class and race when it comes to defining the female subject (Ayala and Mateo 1999). Judith Butler is one of the most renowned authors within the Post-feminist movement and contemporary feminist philosophy, and her theories sustain some of the main arguments posed by this study. Her ideas have had relevant consequences for the current perspectives on gender identity and feminism. She suggests a changing and performative conception of gender to overcome the binary gender system that has traditionally imposed cultural laws and a "unique line of connexion among biological sex, 
culturally constituted genders, and the "the expression" of both in the manifestation of sexual desire through sexual practice" (1990: 283).

\subsection{Defining gender and gender stereotypes}

From the previous statements, it emanates the idea that, if gender is culturally constructed, the study of gender is extremely relevant for the social sciences, as they are determined by the fact that "culture shapes individual social cognition, which in turn contributes to the dynamic reproduction of culture" (Lyons and Kashima 2001: 389). In the same light, a parallelism can be found with "the philosophical polarity between free will and determinism of construction of gender" (Butler 1990: 281) - an aspect that implies that the study of gender should be interdisciplinary because gender is developed by socialization, and its agents and forces influence and affect several fields of our lives.

Although there is not a clear-cut definition of gender, this study draws on Butler's and Basow's theories since their conceptions of gender try to overcome the binary gender system in which "feminine and masculine are understood as opposite and where there are some identities that cannot exist such as, gender that does not follow from sex or sexual desire that does not follow gender" (Butler 1990: 283). Thus, this binary system is one of the bases of the gender stereotypes that wants to be addressed in this pedagogical study. In keeping with this, Butler defines gender as: "King of doing, an incessant activity performed [...] it is a practice of improvisation within a scene of constraint. Moreover, one does not "do" one's gender alone. One is always "doing” or for another" (2004: 1). Further, in her book Gender Stereotypes and Roles Basow defines sex as "A biological term; people are termed either male or female depending of on their sex organs and genes" (2). However, since the moment when she made this statement in the early 1990 s, the criteria of using sex organs for classifying persons as women or men has started to be seen as insufficient. This explains that now gender is conceived as a "psychological and cultural term, referring to one's subjective feelings of maleness or femaleness (gender identity). Gender may also refer to society's evaluation of behaviour as masculine and feminine (gender role)" (2).

Thus, even though the distinction between sex and gender seems to be clear, people tend to use these concepts as synonyms and assume that gender differences are based on biology. Basow refers to such thinkers as Deux and Kite (1987), who suggest that the answer to this lies in a shared "gender belief system" which refers to "a set of beliefs and opinions about males and females and about the purported qualities of masculinity and feminity" (3). In the light of their ideas, she finds that gender belief systems influence the way we perceive and evaluate others, which is shaped by two key elements: gender roles and gender stereotypes because, according to her, "gender stereotypes are those structured sets of beliefs about the personal attributes of women and men" (3). They are strongly held over generations, universally shared within a given society, learned as a part of the growing process, they are normative and desirable, and they are set up by a self-fulfilling prophecy based on social and personal expectations, existing both on a cultural and personal level.

In addition to this, Basow notes that, although the great influence of gender stereotypes is reflected in personality traits, they also exist in three other related areas: masculine and feminine roles, masculine and feminine occupations, and masculine 
and feminine physical characteristics. In consequence, the influence of gender stereotypes goes beyond personality and affects behaviour, occupational options and health issues. Finally, another implication of gender stereotypes is that they provide a binary view of women and men, leading to the misleading conclusion that there are exclusively masculine and feminine traits.

\subsection{The origin of gender stereotypes and the process of socialisation}

Regarding the origins of stereotypes, Basow states that "although some differences exist and may have a physiological basis, the bulk of the research suggests that gender differences, to the extent they exist, are a function of gender roles rather than a cause" (1992: 11). Drawing on this, the theory that guides this study focuses on this social role, which underlines socialisation as the origin of the process of stereotype formation. "The social role theory" states that stereotypes arise from roles and jobs typically held by women and men, and the distinct skills developed by women and men due to this. Thus, these skills and abilities are assumed as innate by the society, reinforcing stereotypes.

Therefore, socialisation becomes the essential process in which roles and stereotypes are transmitted. Summarising quite a lot, the gender schema theory used for our study should be read in parallel to three other socialisation theories: psychodynamic theories, social learning theory and cognitive-development, including an active role for children when developing concepts of gender identity and organising the world consistently with their level of cognitive development. Gender schema theory believes that the child, when observing the distinctions made between males and females by the social agents immersed within a given culture, develops the gender schema, which are cognitive structures that serve to organise and guide individual perceptions and future gender identities.

In addition to this, Basow explains that, together with this intertwined vision of the socialising process, a life-span perspective has to be considered since gender identity keeps on developing into adulthood. She presents a model of gender identity integrating social and environmental factors based on the model of Katz A. Phyllis. According to this model, ${ }^{5}$ it... can be realised that it is vital that social agents do not transmit rigid gender schemas in order to allow future children to grow in a free and egalitarian society. Focusing on the period of late childhood and early puberty with which this research is concerned, this model of gender identity supports the idea that during early childhood, children have rigid stereotypes, but at the age of eight their stereotypes become more flexible and dimensional and, thus, "people could be classified as sex typed individuals (they have a bipolar construct for masculinity/ feminity and then, they understand the world from a stereotypic perspective) and non-sextyped individuals (absence of a strong gender schema)" (Basow 1992: 126). This means that when they reach late childhood and early puberty, the age of the students that have been selected for this study, children have built the basis of their gender schema, and they understand the world according to them. In addition to this, sexual orientation begins to develop during puberty and students' curiosity about it has a twofold effect: they are motivated to discover sexuality and sexual orientation but, at

Katz's model analyses the role of the environmental factors in constructing gender identity since children are born to adulthood and concludes that their influence is enormous (1996). 
the same time, it is quite usual to resolve doubts and unknown information by having recourse to stereotypes.

\subsection{School and gender stereotypes}

As has been mentioned so far, socialising agents and forces affect the development of gender assumption, and these may be parents, teachers and peers, and forces like the language, play, School, religion and the media. Although all of them have great relevance, language, the School influence and all its related aspects are exposed in this study.

Several researchers have written about the influence of the School in the transmission of culture and its values. One well-known theorist of this field is Pierre Bourdieu, who critically analyses the School as an agent of reproduction of a given culture that benefits the dominant classes and imposes exclusions and inclusions which are the basis of the social order (Bourdieu and Passeron 1990: 10). Furthermore, according to Bottemore, "Pierre Bourdieu also states that the revision of the pedagogic action and of the whole process of cultural reproduction, itself generates or modifies theoretical conceptions of the structure of dominant and subordinate class and groups" (1976: xi). Although this theory might seem quite distant from the analysis of the stereotypes transmitted by the English teaching materials, Bourdieu identifies education as the mechanism that transmits culture; therefore, it also transmits stereotypes, and we should revise our pedagogic action to change the patriarchal social structures.

Concerning this, School organisation also transmits an unconscious hierarchical system. Specifically, in the Spanish primary school system, several studies have concluded that the proportion of headmasters is superior in comparison to the proportion of headmistresses. And, as the level of education increases, this distinction becomes even more evident (CIDE and Instituto de la mujer 2004). Although the study carried out by the CNIIE and the Instituto de la mujer in 2011 points out that this distinction has been reduced, due to the fact that the percentage of headmistress has considerably increased in the last six years in the three compulsory educative stages, women have still more presence in managerial positions in Nursery and Elementary Education. Another aspect to underline is that the gender of teachers usually differs depending on the subject. The teacher can provide additional messages regarding sex role development through the provision of activities, modelling and subtler forms of gendered-biased communication. These behaviours have their origin in the teacher's stereotypic gender schema and then, it is essentially relevant that teachers are aware of them in order to change their teaching practices.

Regarding the teaching materials, they are an indispensable aspect of formal education. They could be understood as all the materials used during the learning process such as textbooks, reading books, films or music. In this study three textbooks are going to be evaluated because, as Terrón and Cobano-Delgado (2008) expose and also drawing on Zabala's theories (in Peiró 2001), the textbook is the element which guides and provides the essential structure of pedagogical practice and most of the decisions concerning contents and pedagogic strategies (Terrón and Cobano-Delgado 2008: 387). Other authors like Sayilon have claimed that "textbooks are the very tools which continue to transfer gender inequality and patriarchal ideology" (in Kalayci and Hayirsever 2014: 1068). Moreover, as Sunderland et al. have claimed when 
referring to the specific case of foreign language textbooks, "these books can be seen as data worth examining for their gender significance because they are characteristically densely populated with people who are not only in social relationships with each other, but who continually verbally interact with each other" (2002: 223). Thus, teachers have the responsibility to evaluate the textbooks that they use and make sure that they are free of gender stereotypes in order to create an inclusive environment in the School.

Lastly, we should not forget about language, as it is considered to have a significant role in defining and maintaining male power over women (Tran-Hoang-Thu 2010). Also following Basow (1992), sexism in the English language may take three major forms: firstly, ignoring females by using the masculine gender to refer to human beings in general. Stereotyping also defines women by labelling what is considered to the exception to the rule like "lady doctor" or "policeman". Secondly, the status of the females is also defined by the order in which they are usually mentioned, being usually the second place. And finally, deprecating either by trivialising or sexualising women is the last form to maintain male power over women.

\subsection{Language teaching approaches}

Despite the vast variety of methods that have been used in the context of English Foreign Language teaching, nowadays, the communicative language approach inspired by the concept of communication championed by Hymes (1973) seems to be the most relevant, which is complex to define due to the fact that this approach has several interpretations (Harmer 2015). Yet there seems to be a consensus in its basic features: meaning is paramount, language must be contextualised and authentic, production of language is encouraged from the start, and activities are designed to give opportunities for communication and meaningful learning (Richard 2006).

Nevertheless, it seems difficult to stick to one single method for English language teaching if we want to adapt our teaching to the real and diverse context of the classroom. Therefore, some researchers consider that we are currently living a post-method phase (Harmer, 2015). As Kumaravadivelu stated, we need an "alternative to method" (2006: 67) because using a single method has a limited and limiting impact in language teaching and learning. The post-method approach embraces the critical pedagogy that "it is about recognising language as ideology, not just as a system and is about extending the educational space to the social, cultural and political dynamics of language use, not just the phonological, syntactic and pragmatic domains of language usage" (70). According to this view, it can be fathomed that the post-method advocates teaching English from a more social, political and contextual perspective, which turns it into a suitable approach to teach gender awareness in the classroom.

Therefore, this study is going to follow the communicative approach combined with this post-method because the former is the one more generally present in contemporary English teaching materials and the latter includes a more socio-cultural contextualized use of the second language ${ }^{6}$ Attending to this, the need to review the

One of the key principles of the communicative approach has to do with the Task Based Instruction, which, in words of David Nunan, is the realisation of Communicative Language Teaching philosophy (2004: 10), because it makes the performance of meaningful and communicative tasks central to the learning process (see Hamer 2015). 
teaching materials and the perceptions of the students in the English classroom is also justified because the different meanings negotiated, exchanged and acquired by the communicative tasks developed in the classroom will be part of the meanings that in the end contribute to shaping the students' gender schema.

\section{Methodology}

\subsection{Surveys}

Two different surveys were carried out for the purpose of this study. They were designed according to the orientations suggested by Siniscalco and Auriat (2005), who state that the first step to follow is to identify the aims of the surveys and, afterwards, design the questions according to the classification of closed and opened questions. Furthermore, the questions were adapted to the target population. For instance, in the case of the students' survey, although the questions were in English, the vocabulary was simple and they had the opportunity to answer them in Spanish. Moreover, as this survey attempted to collect and analyse attitudes, in order to examine the data as objectively as possible, the techniques of attitude scales, which "consist of a number of attitude statements which are presented to respondents with a request that they should indicate whether they agree or disagree" (Siniscalco and Auriat 2005: 55) or the grade in which they agree or disagree, were used. Both surveys were designed thanks to an online application and they were sent by email to the intended population. The first survey was intended for all English teachers of $6^{\text {th }}$ grade of Primary Education in Aragón. It was sent to every state, private and subsided-state schools of this region. Consequently, the second one was addressed to the students that attended the classes of the teachers who had answered the first survey.

In terms of content, the survey for teachers was elaborated to analyse the teachers' opinion about the influence of the English textbooks in the formation of gender stereotypes and transmissions of values. They were also asked about the teaching materials that they were currently using in their English classroom, their experiences with students and their academic training in relation to gender stereotypes. The students' surveys were designed to analyse the influence of images in the students' perception, their linguistic biases when choosing some words to refer to men and women, their conceptions about the job spheres and male/female tasks, and their interest in this topic.

\subsection{Collecting data and analysis of the results of the surveys}

From the results of the teachers' surveys, the titles of the textbooks and extra materials that have formed the corpus of research were extracted. Of those titles, the three most frequently used textbooks were chosen: Quest 6, Great Explorers and Rooftops 6.

\subsection{Design of the checklist for the analysis of the textbooks}

To analyse the three textbooks objectively and rigorously, three different checklists were developed: one for analysing the linguistic level, another for the graphic level and a final one focusing on the representation of clothes. 


\section{Linguistic level checklist $^{7}$}

\begin{tabular}{|l|l|l|l|}
\hline \multicolumn{1}{|c|}{ Criteria } & Women & Men & Both/ Comments \\
\hline $\begin{array}{l}\text { 1. Attitudes and feelings in } \\
\text { conversation, adverbs, adjectives, } \\
\text { and prepositional phrases }\end{array}$ & & & \\
\hline $\begin{array}{l}\text { 2. First place of concurrence in } \\
\text { conversations }\end{array}$ & & & \\
\hline 3. Omissions & & & \\
\hline $\begin{array}{l}\text { 4. Firstness (which gender } \\
\text { appears first in grammar and } \\
\text { mentioning names) }\end{array}$ & & & \\
\hline $\begin{array}{l}\text { 5. Frequency of male and female } \\
\text { mentions (pronouns, nouns) }\end{array}$ & & & \\
\hline 6. Famous people & & & \\
\hline 7. Gender roles (jobs) and actions & & & \\
\hline 8. Hobbies & & & \\
\hline 9. Private environment & & & \\
\hline 10. Public environment & & & \\
\hline
\end{tabular}

\section{Graphic Level checklist ${ }^{8}$}

\begin{tabular}{|l|l|l|l|}
\hline \multicolumn{1}{|c|}{ Criteria } & Women & Men & Both/Comments \\
\hline 1. Attitudes and emotions & & & \\
\hline 2. Gender roles (jobs) and actions & & & \\
\hline 3. Frequency of illustrations & & & \\
\hline 4. Famous people & & & \\
\hline $\begin{array}{l}\text { 5. Different types of families, } \\
\text { relations or couples }\end{array}$ & & & \\
\hline 6. Hobbies & & & \\
\hline 7. Private environment & & & \\
\hline 8. Public environment & & & \\
\hline 9. Sexless drawings & & & \\
\hline
\end{tabular}

7 Each item of each checklist referred to is based on the theories that have been explained in the second section of this article.

8 Criteria 1,3,7,8 and 9 are based on Carrón \& Cobano's study and criterion 2 is based on Dominguez's. 
Clothes and accessories Checklist (based on Terrón and Cobano-Delgado 2008)

\begin{tabular}{|l|l|l|l|l|l|}
\hline \multicolumn{1}{|c|}{ Variable } & Clothes & Girls & Women & Boys & Men \\
\hline $\begin{array}{l}\text { 1. Types of } \\
\text { Clothes }\end{array}$ & & & & & \\
\hline Jeans & & & & & \\
\hline Shorts & & & & & \\
\hline Sweatshirt & & & & & \\
\hline T-shirt & & & & & \\
\hline Dress & & & & & \\
\hline Trousers & & & & & \\
\hline Skirts & & & & & \\
\hline Shirts & & & & & \\
\hline Suit & & & & & \\
\hline Trainers & & & & & \\
\hline Shoes & & & & & \\
\hline Heels & & & & & \\
\hline Tracksuits & & & & & \\
\hline Uniforms & & & & & \\
\hline 2. Accessories & & & & & \\
\hline Tie & & & & & \\
\hline Bag & & & & & \\
\hline Glasses & & & & & \\
\hline $\begin{array}{l}\text { Earring, } \\
\text { necklace, } \\
\text { bracelet }\end{array}$ & & & & & \\
\hline $\begin{array}{l}\text { Working clothes } \\
\text { (pants) }\end{array}$ & & & & & \\
\hline Apron & & & & & \\
\hline Sward & & & & & \\
\hline Cap/hat & & & & & \\
\hline Watch & & & & & \\
\hline Headband & & & & & \\
\hline
\end{tabular}




\section{Colours and clothes checklist ${ }^{9}$}

\begin{tabular}{|l|l|l|l|l|l|l|l|l|l|l|l|}
\hline Girls & & & & & & & & & & & \\
\hline Women & & & & & & & & & & & \\
\hline Boys & & & & & & & & & & & \\
\hline Men & & & & & & & & & & & \\
\hline
\end{tabular}

\subsection{Data collection: Analysis of the textbooks}

The process for the analysis of each book was the following: firstly, the texts, grammar sections, pictures and drawings of each unit of the textbook were analysed. Then, all the quantitative and qualitative results were selected and summarised in three general tables that organised the data of the three checklists of each textbook. Finally, these tables became the basis for the comparative analysis and discussion of the results.

\section{Results and discussion}

\subsection{Teachers' survey results}

The surveys were answered by 40 teachers from 26 Aragonese state schools of which 22 were rural and, 4 subsided-state schools, of which 3 were Catholic. The results show that $80 \%$ of the teachers had not received any training on the influence of gender stereotypes over students. This is remarkable because the lack of training in this area makes the teachers unaware of its relevance, which can lead them to be more vulnerable to choose materials that contain sexist stereotypes. Also, this fact could explain why $22.5 \%$ of the teachers answered "Do not know" to the question: "Do the English textbooks and extra teaching materials that you use influence the formation of gender stereotypes?" This means that they are not aware of the socialisation process in which gender stereotypes are transmitted and, therefore, they will not be critical with the materials they use.

Regarding the aspects that the teachers consider when choosing a textbook, the following graphic portrays their answers:

According to Karniol (2011), they are decisive for labelling gender. 


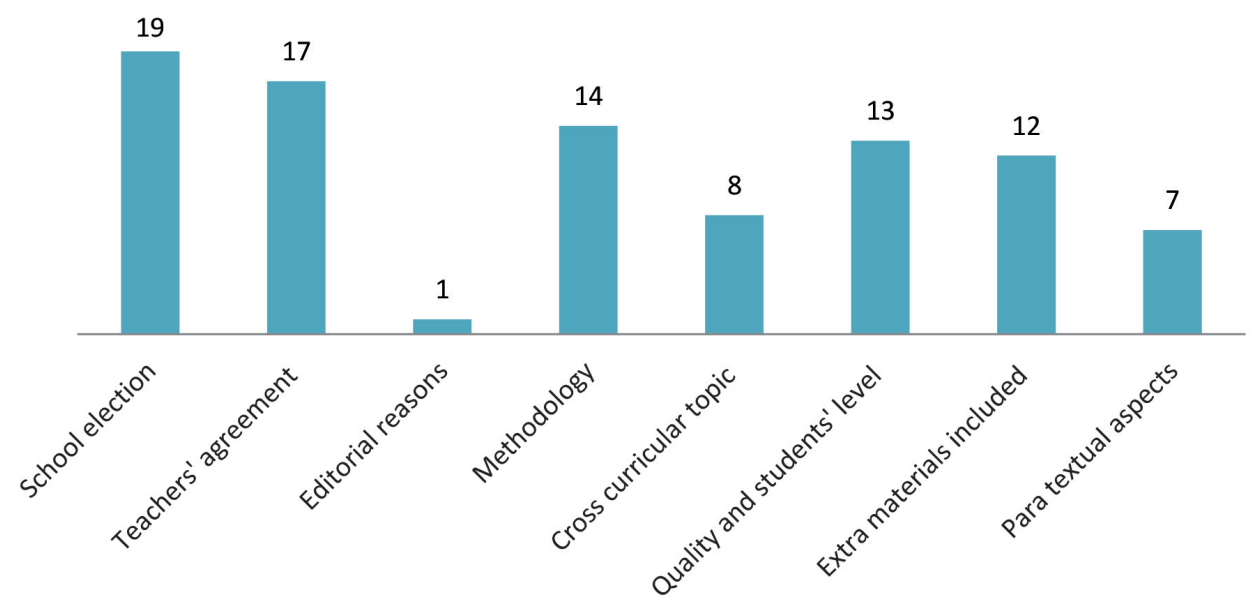

Figure 1. Reasons for choosing textbooks.

The school election and the teachers' agreement are the aspects that the teachers consider when choosing a textbook because they want to provide consistent teaching among the different classes. Nevertheless, the cross-curricular topics offered by the textbook are the second aspect less considered, which is quite contradictory to the curricular premise (see Orden del 9 de Mayo, Disposición Quinta, 20) that the teaching materials should promote cross-curricular values.

\subsection{Analysis of the textbooks}

As has been mentioned before, the three most used books in Aragón were analysed: Quest 6 (2012), Great Explorers 6 (2015) and Oxford Rooftops (2015). The most remarkable characteristics identified in the checklist exposed comparatively and according to the levels of analysis, linguistic level, graphic and clothes, will be now presented.

\subsubsection{Linguistic level}

a) Attitudes and feelings in conversation, adverbs, adjectives and prepositional phrases

This item analyses the attitudes and feelings in the conversation, adjectives and prepositional phrases, and not only the word level. According to the results, common emotions and attitudes that are attributed to women are: being caring, interested in clothes and scared, whereas men are assigned characteristics like being confident, having initiative and being involved in actions concerning money.

If the three books are compared, it is clear that Quest 6 portrays women and men with opposed characteristics. For instance, in the readings the boys usually solve the problems while the girls are more dependent on boys' opinion. Another attitude to underline is being scared, considered common for women while it does not appear as a boys' feature. In Great Explorers once a man appears scared, but his wife penal- 
ises him by saying "You have to be brave, Ronnie". About Rooftops, although girls look scared in some dialogues, boys are portrayed with no opposed characteristics, and boys and girls share attributes like being clever and ambitious. Thus, Quest 6 and Great Explorers have some sexist commentaries or attitudes, and Rooftops presents men and women more equally.

b) The amount of talking

The amount of talking of male and female characters has been measured with two variables: firstly, the place of appearance in conversations, and secondly, the frequency of male and female mentions (Dominguez). The first place of appearance in conversations shows the initiative of talking. For this, only the conversations between two characters were considered. About the frequency of male and female mentions (nouns and pronouns), all the gendered nouns and pronouns that appeared in the texts have been counted:

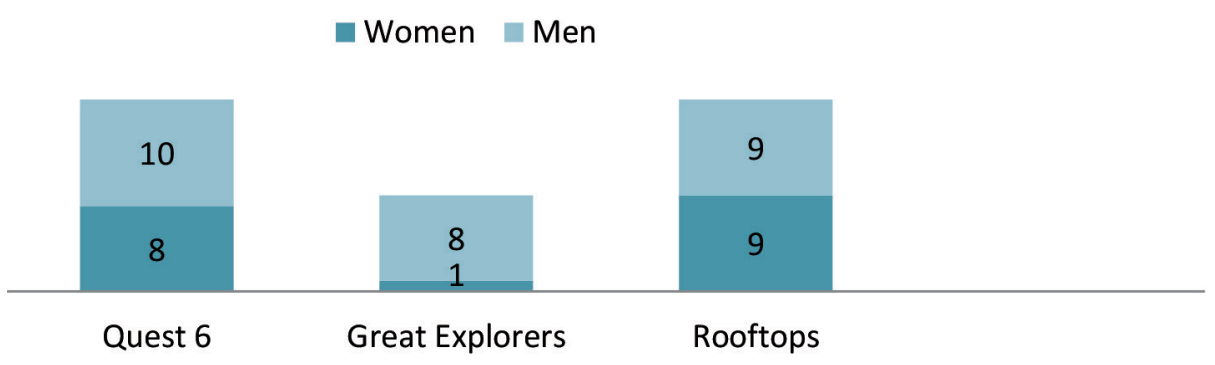

Figure 2. First place of concurrence of males and females in conversations.

As the graphic portrays, the first place of males and females in conversations is quite equal in Quest 6 and Rooftops, whereas in Great Explorers men have the initiative.

However, the amount of male mentions is superior to the female ones in the three cases. Being the male mentions in Quest $659.6 \%$, in Great Explorers 54,6\% and in Rooftops $65.4 \%$.

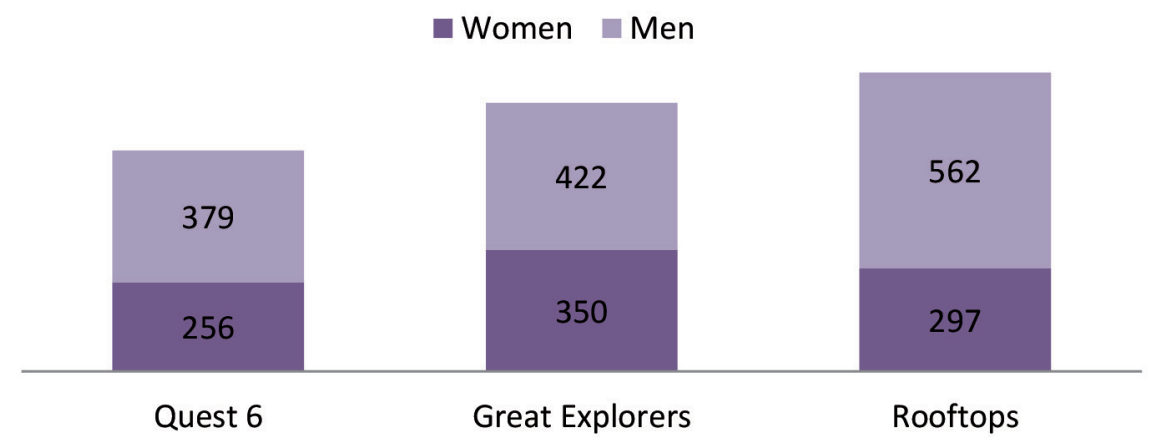

Figure 3. Frequency of male and female nouns and pronouns. 
c) Firstness

The concept of Firstness, initially defined by Porreca, refers to the situation in which "given two nouns paired for sex, such as male/ female, the masculine word always came first" (in Dominguez 2003: 706), but in this study it is going to be applied to female pronouns and nouns that appear at the beginning. The importance of this aspect resides in the fact that the pronouns and names that are written first transmit a sense of relevance appear at the beginning of a construction.

\begin{tabular}{|l|l|c|c|c|}
\hline \multicolumn{1}{|c|}{ Firstness in } & \multicolumn{1}{|c|}{ Gender } & Quest 6 & Great Explorers & Rooftops \\
\hline \multirow{2}{*}{ Grammar } & Women & - & 4 & - \\
\cline { 2 - 5 } & Men & 41 & 2 & 13 \\
\hline \multirow{2}{*}{$\begin{array}{l}\text { Mentioning } \\
\text { names }\end{array}$} & Women & 6 & 4 & 11 \\
\cline { 2 - 5 } & Men & 2 & 3 & 7 \\
\hline
\end{tabular}

Figure 4. Firstness.

It may be observed that two of the textbooks, Quest 6 and Rooftops, in their grammar sections, show that male pronouns are written first. However, Great Explorers alternate the order in which feminine and masculine pronouns are written. Nevertheless, the feminine "Firstness" when mentioning names is superior in all the cases.

d) Famous people

One way to teach culture in the classroom is talking about important personalities in the English-speaking countries. However, Munden identifies that sometimes teaching about famous feminine personalities could be difficult for teachers because women are usually excluded from our cultural background.

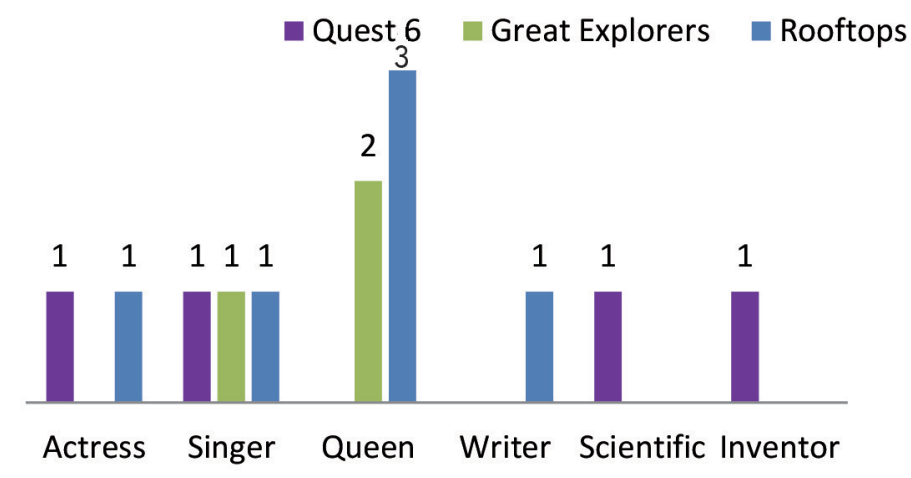

Figure 5. Female personalities. 


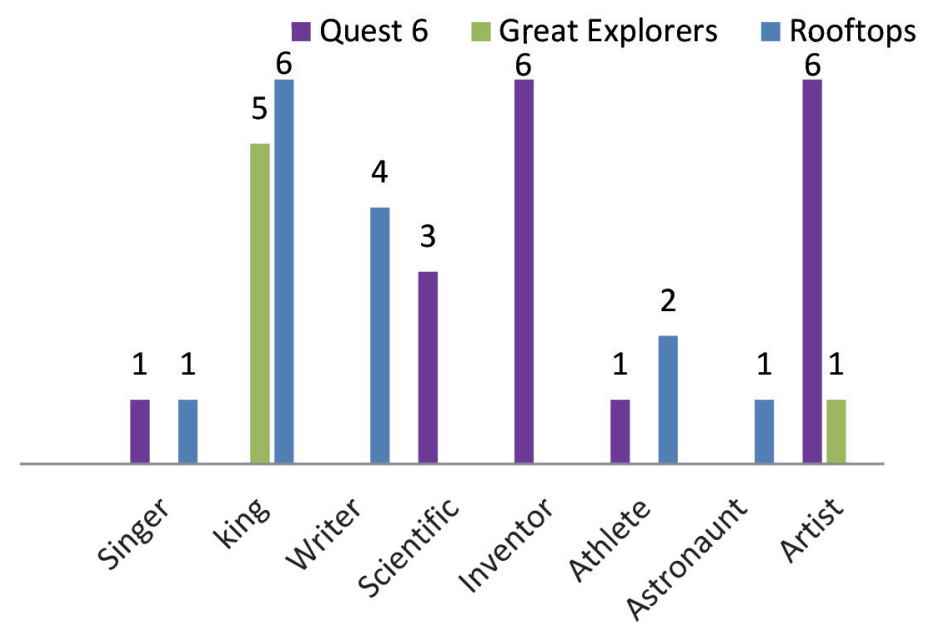

Figure 6. Male personalities.

The data show that famous women are less represented and, when they are, they are usually actresses, singers, queens or princesses, and they are not usually represented in the scientific field, while the variety of male personalities is higher including characters within artistic, royal, literary, sport and scientific fields.

\section{e) Occupational roles}

As the previously exposed theories about social roles and stratification demonstrate, as well as materialist feminism points out ${ }^{10}$, the gender-based division of labour has been the origin of numerous gender stereotypes. Therefore, it is imperative that textbooks do not hold traditional occupational roles.

The results demonstrate that some traditional occupations like teachers, doctors, athletes and chefs, are representative in women and men. However, there are some traditional occupations that are still held by women, like models and dancers and others like police officers, sellers and football players are held by men. Specifically, Rooftops could be considered the least job stereotyped because there are many jobs in which women and men are represented coach, inventor or athlete and because some of the women have political power, like the major of the town. Quest 6 contains the highest stereotyped jobs because women are less represented in labour world, they hold stereotypical jobs like model and milkmaid and women's working aspirations are not reflected, while men are mentioned as TV presenters, scientists and police officers. Regarding Great Explorers, women and men do not hold a high number of stereotypical occupations; they are both represented as security guards, taxi drivers, nurses and shop assistants. However, women and men do not share

10 Materialist feminist Sherry Ortner (1974) states that the division of labour entails the concept that women belong to the private sphere and men to the public one. For further reading on this, see Phillips and Cree's redefinition of these theories (2014). 
many occupations; women appear working as cleaners, doctors, scientists or Math teachers and men are represented as postmen, teachers and cooks on TV.

\section{f) Gender roles}

In relation to this, women are usually identified with the familiar environment and men with the public world. The results show that most of the women's roles especially mothers' and grandmothers' are related to the familiar environment, either cooking or taking care of the children. While men, especially fathers, are resting, taking responsibility for the family in special situations like going to the museum or the football stadium, and only cooking in the garden. Further, there are also some sexist expressions in Quest 6 like "Sing like a woman" and "talk like a man" (25) and some stereotypical attitudes in Rooftops like "mum eats fruit and dad eats meat" (86).

\section{g) Hobbies}

Hobbies also define people's personality and abilities. Attending to the results, girls and boys do often hold non-traditional hobbies such as dancing or playing with dolls for girls and playing with technology for boys. Although girls and boys do not usually have the same hobbies in the textbooks or have few hobbies in common, these books relate team sports to both, but playing football is still only associated with boys.

\subsubsection{Graphic level}

The analysis of the graphic level draws on the belief that illustrations are a decisive element of the definition of a textbook and they are an essential transmitter of contents (Terrón and Cobano Delgado 2008). Some of the items previously analysed at the linguistic level are going to be examined graphically because the values and content transmitted by the text sometimes do not agree with the ones transmitted by the images.

\section{a) Attitudes and emotions}

The results show that women are often portrayed as polite, admiring something or someone because of their beauty, with weaker emotions like crying or being scared, and they usually appear posing like models. Moreover, men usually appear posing in a natural way or relaxed, thinking, having ideas (raising their hands) and related to money (buying, earning money). Although in every textbook stereotypical images of women and men appear, the least stereotyped is Rooftops because a female character that appears repeatedly on the book is the major of the town. Furthermore, girls appear on many occasions succeeding in sport competitions which are usually portrayed in masculine world.

b) Famous people

With regard to famous people, there is the same tendency as the one observed at the linguistic level: 


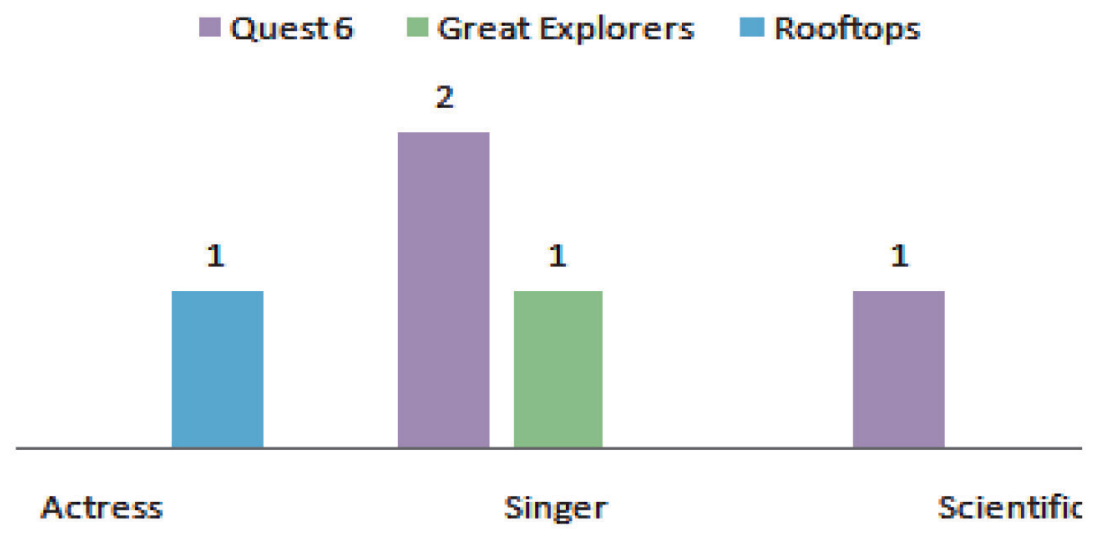

Figure 7. Female personalities.

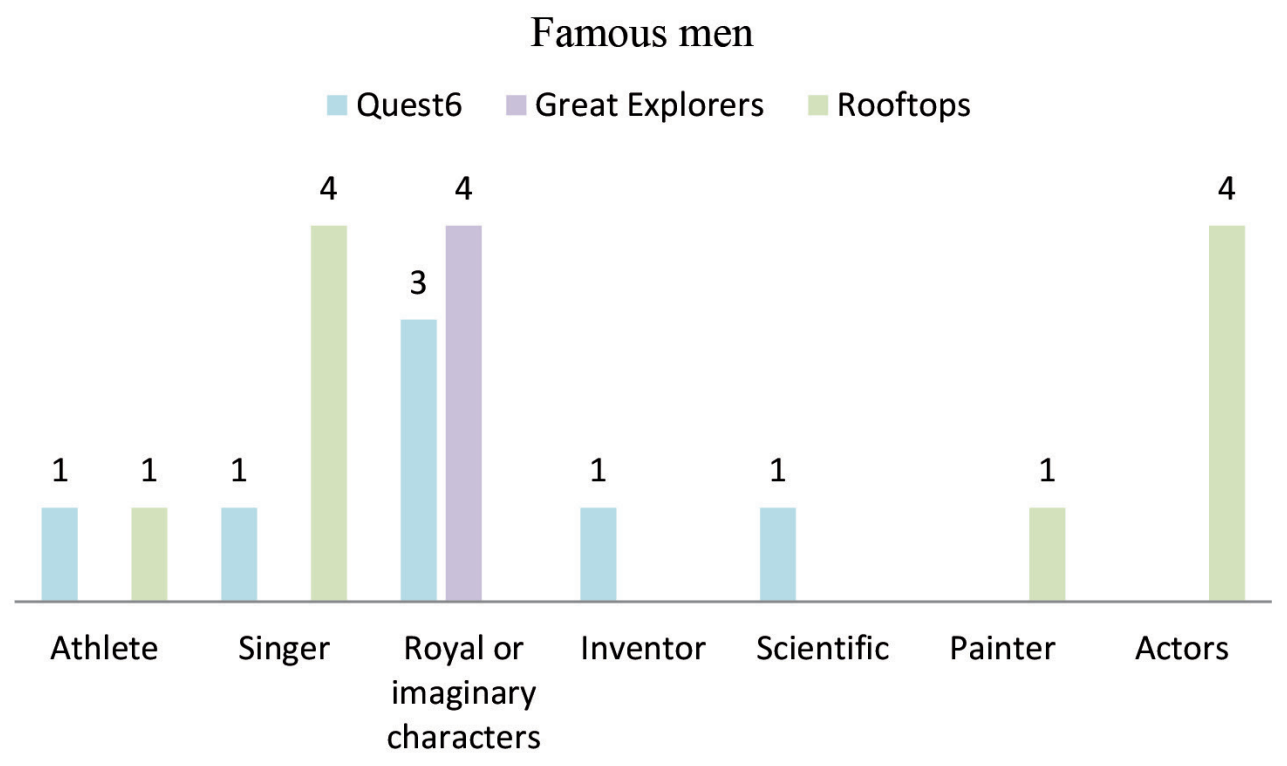

Figure 8. Male personalities.

c) Occupational roles

At the graphic level, there is not a huge difference between the jobs that women and men hold. It is clear that Quest 6 presents a stronger binary system of labour as it presents men with intellectual and scientific jobs while women are portrayed with "assistant" jobs. Both Great Explorers and Rooftops portray women and men with different jobs, including intellectual and scientific jobs. 
d) Gender roles

The gender roles portrayed in the three textbooks follow the tendency of identifying women with the house environment, cooking and taking care of the children, especially for mothers and grandmothers; while men represented in leisure activities and doing repairing chores like painting a fence.

However, at the graphic level some aspects that are not reflected throughout the linguistic level appear, like boys picking berries and dancing, which are activities traditionally identified with girls, and boys and girls studying and playing together. But at the same time, other images reinforce gender roles, such as mothers taking care of the children and cooking. These images are especially repeated in Rooftops, where different fathers appear uniquely cooking in the garden on special occasions and women are responsible for the daily meals in the kitchen.

e) Frequency of illustrations

Every character that appears in photos or drawings has been counted. The results show that the frequency of male illustrations is always superior, being the male representation in Quest 6 58\%, in Great Explorers 52\% and in Rooftops 57.7\%.

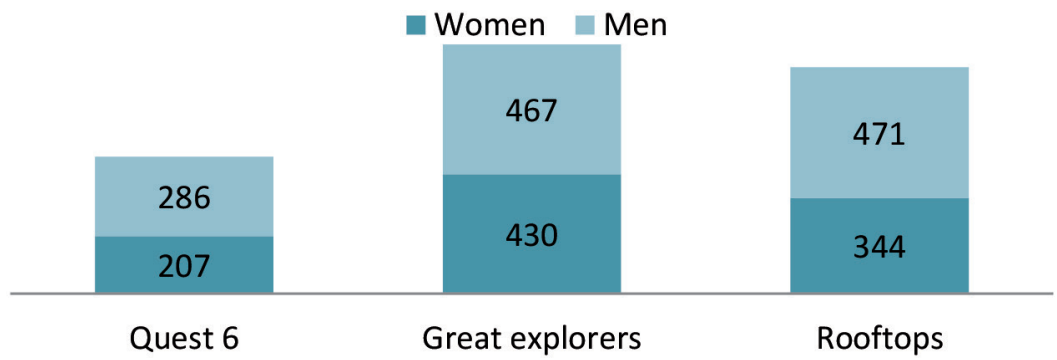

Figure 9. Frequency of illustrations.

\section{f) Hobbies}

As happened with the linguistic level, the portrayed hobbies are also varied for girls and boys. Moreover, Great Explorers and Rooftops include some images that promote non-differentiated hobbies for girls and boys because they do many activities in common. Some traditional activities for boys like playing football or video games are also portrayed in girls, and some activities like dancing or doing homework are attributed to boys.

h) Different types of families, relationships and couples

The analysis of the visibility of different types of families and relationships has been examined graphically and the results show that there are not any different types of families, apart from the traditional one composed by a heterosexual couple, their children and sometimes the grandparents. Therefore, other types of families like di- 
vorced parents, homoparental or single-parent families are completely invisible in these textbooks.

In particular, Rooftops is the textbook that underlines the traditional family, appearing five times in the illustrations and heterosexual relationships portrayed 13 times. This invisibility of different families, together with the strong gender roles that are attributed to women in the private environment, promote the idea that the family should be patriarchal and heterosexual.

\section{i) Sexless drawings}

Terrón y Cobano-Delgado found in their study that it was essential to analyse the ambiguity of sexless illustrations in textbooks as a way of overcoming gender matter (2008: 399). Thus, in this study sexless characters have been analysed, but they have not been found in any textbook, except for Rooftops where two figures appear (see pages 48 and 50).

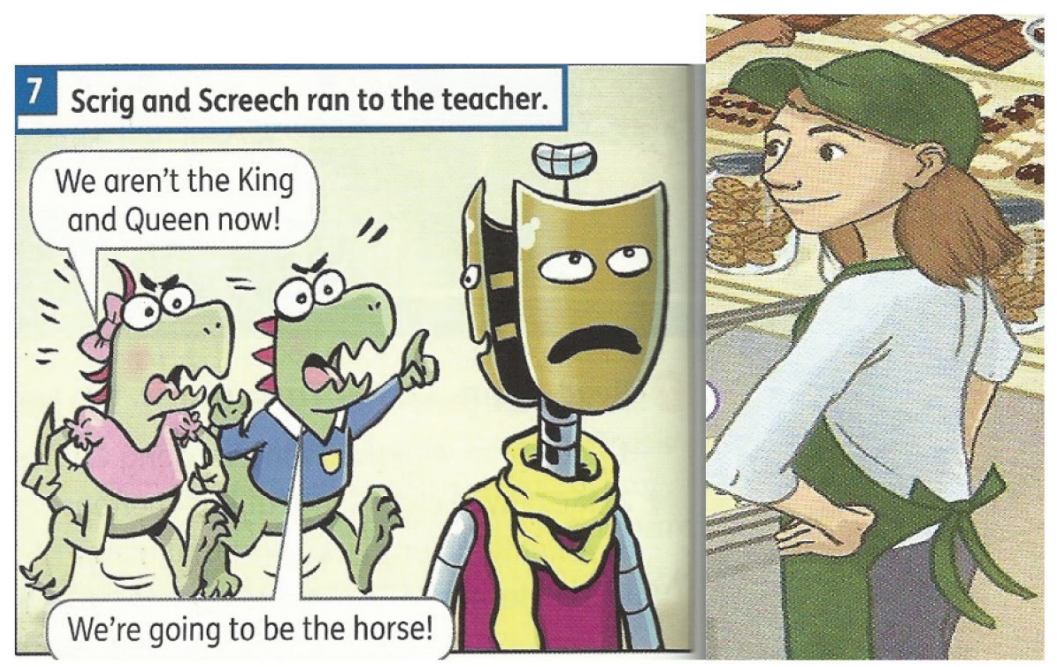

Figure 10. Sexless characters.

\subsection{Clothes analysis}

Colours have an important role in children's emergent gender stereotyping since, according to Karniol, "first reliance on colour allows students to disambiguate ambiguous gender contexts and second, colours drive stereotyped-based expectation as to the association of objects, clothing, disposition, and activities with individuals of a given gender" (2011: 120). This author points out that the warm colours, especially pink and purple, are attributed to girls and the cold ones, mainly in the blue-green range, to boys. Therefore, is essential to analyse the colours in which characters of the textbooks are dressed because they could influence children gender-based roles. Thus, the graphics organise the data of the top five of used colours in girls', women's, boys' and men's clothes: 


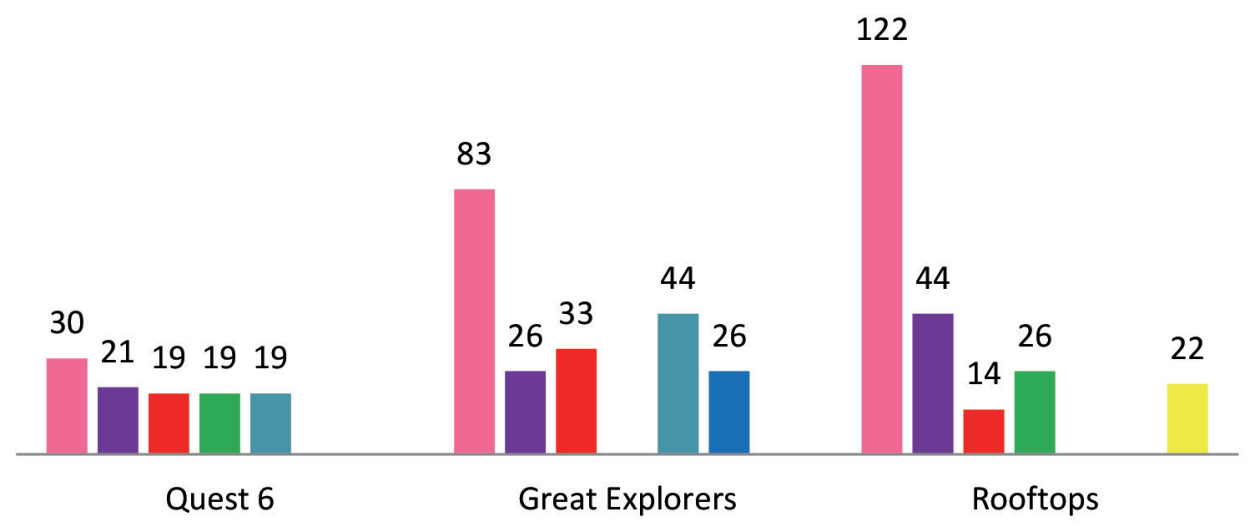

Figure 11. Girls' clothes colours.

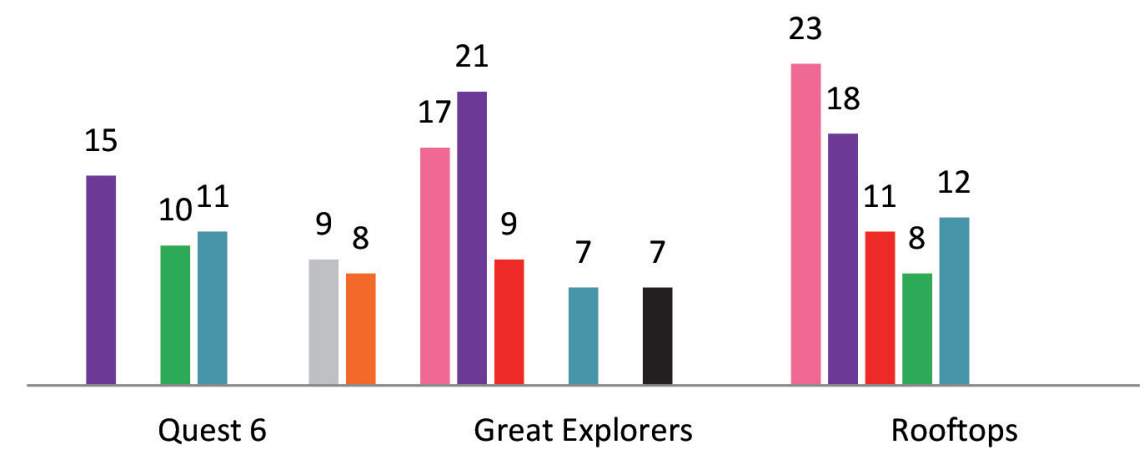

Figure 12. Women's clothes colours.

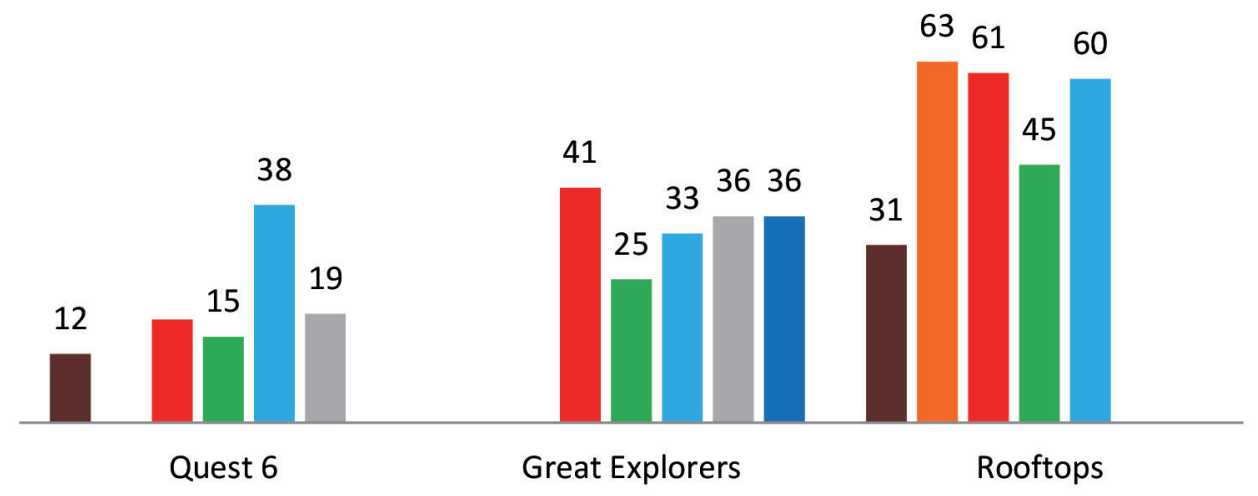

Figure 13. Boys' clothes colours. 


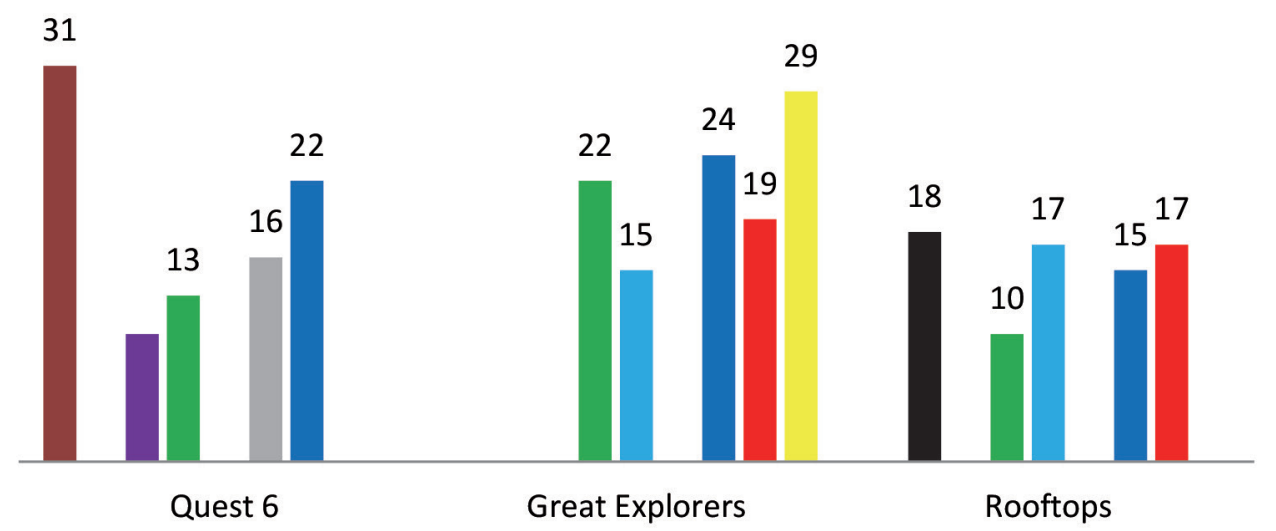

Figure 14. Men's clothes colours.

The graphics demonstrate that there is a huge difference in the use of colours between girls' and boys' clothes. It is clear that in the three textbooks pink and purple are the most used colours in girls clothes, especially in Rooftops, and in boys' clothes they tend to dress in red and light blue and green. However, those colours do also appear in girls clothes.

Other remarkable data with characters' clothes are that in Quest 6 and Rooftops skirts or dresses are the most typical clothes for girls, women in the three books are mostly depicted wearing dresses, and the preferred clothes for adult men are suits of dark colours which symbolise office work. Furthermore, an added accessory to girls' aesthetic is the decoration of their hair with flowers or headbands in every book.

Concerning accessories, glasses as a symbol of knowledge and intelligence, and they are usually portrayed in men and on some occasions in old women. The difference between the number of girls and boys that wear glasses is highly remarkable, especially in Quest 6 where no girl appears wearing glasses while thirty boys wear them, and in Rooftops one girl wears glasses while eighty-five boys wear them.

Attending to the data, Rooftops is the book that portrays the highest number of stereotypical features based on the following aspects colours (girls wearing pink and purple in $72 \%$ of the clothes), the percentage of characters who wear glasses ( $93 \%$ are male) and clothes ( $81 \%$ of the women wear a skirt or dress, only 19 per cent wear trousers).

Considering all these aspects, the analyses of the different levels in each book provide sufficient data to conclude that all the books contain some gender stereotypes or present unequal representation of women and men and, therefore, they promote the formation of rigid gender schema.

Regarding the linguistic level, the analysis of the amount of talk shows that in all the textbooks women are significantly less mentioned than men. Furthermore, one form of linguistic sexism is still persistent in two of the textbooks, Quest 6 and Rooftops, because they usually mention feminine pronouns in the second place. Concurrently, the visibility of women in illustrations is in the three cases minor than the male visibility, being more evident in Quest 6. This is also evident in the quantity and variety of female historical figures. Furthermore, as has been exposed in the theoret- 
ical section, the influence of gender stereotypes is reflected in personality traits. The results show that every textbook portrays and describes women as polite, worried about their aesthetic, and with weaker and warmer emotions; while boys are portrayed or described more naturally and with stronger emotions. This is more or less evident depending on the textbook, and the data suggest that Quest 6 is the most stereotypical and Rooftops present the least stereotypical traits.

However, stereotypes also exist in other areas, like in the representation of masculine and feminine roles, at the graphic and linguistic levels, and on many occasions books also describe women as specially attached to the private sphere. In this sense, it has been difficult to decide which textbook presented more stereotypic gender roles, because all of them present a high number of stereotypes, although Rooftops could be concluded as the most stereotypical in this aspect because the gender roles are strongly opposed to each other. Moreover, stereotypes appear in masculine and feminine occupations, and the data demonstrate an optimist perspective in this field because all the books, to greater or lesser extent, introduce characters with non-traditional jobs according to their gender. However, there are still some jobs, like dancer or police officer, which are not represented in both genders.

With regard to hobbies, the panorama is also optimistic, especially at the graphic level, because characters are portrayed doing non-stereotypical activities according to their genders concretely in Rooftops and Great Explorers. However, girls and boys do not usually appear carrying out the same activities, primarily in Quest 6. In relation to the fact of not sharing activities, this could be analysed as a stereotypical male attitude, avoiding stereotypical feminine activities, traits and preferences. This is particularly evident in the use of colours and the clothes that the characters wear in the textbooks.

Finally, the visibility of other types of families and homosexual relationships are absent in the three of the textbooks; which is worrying because the lack of information about this reality is usually compensated by using stereotypes.

Attending to the data, Quest 6 could be classified as the most stereotypical of the three textbooks. However, it is difficult to decide which book should be the most suitable to use in the classroom because all of them present certain stereotypical values and unequal attitudes in different aspects. Therefore, the election of one book or another depends on the professional assessment of those aspects that are more determinant when developing these stereotypes.

\subsection{Students' survey results}

The survey aimed to analyse if the students in the $6^{\text {th }}$ year of Primary School had a strong gender schema. The students $(44.7 \%$ were male, $54.9 \%$ were female and $1.3 \%$ other) who answered the survey belonged to three rural state schools, CEIP Santos Samper, CEIP Montecorona and CEIP Monte Oroel (26 students answered the survey).

As regards to the influence of images in the students' perceptions, the results show that the images had highly influenced the perceptions of the students, just the fact of attaching a picture to the same question partly changes students' perceptions, especially, if the image is stereotypical. Furthermore, the students were also asked to continue the beginning of a story. The results of the students' written production show that there are 43 elements of the stories that contain gender stere- 
otypes: students regard gender in a very stereotypical way, and they express gender schema in the text through sexist attitudes. Even some stories show gender violence against women: psychological violence, the submission of the princess to the boy she likes; and in the other story, the physical violence when the man kills the princess because he is angry also appears. These stories are examples that justify the need for teaching gender awareness if we want to avoid this future type of behaviour. However, some stories show that some students do not have stereotypical gender schemas and, consequently, they do not express sexist elements. In these stories, the princesses are presented as independent people who do not need to be saved by a man. For example, one of the students wrote this final for the story: "The princess thought that she should escape and that was she did. She went out of the castle as fast as possible so that she could travel and discover the world". And another relevant example could be that of the student who chose as the ending the following words: "One day, the princess escaped from the castle and she met an intelligent boy, but when the time passed she was not happy, so she decided to meet new people".

The data shows that $90 \%$ of the students wrote first the pronoun "he" or the equivalent one in Spanish and that in case of omission of any pronoun, this is usually the female one. Thus, we should remember that the analyses of the three textbooks demonstrate that two of them always present the pronoun "he" first and in second place the pronoun "She", results that are aligned with the analysis carried out in the textbooks.

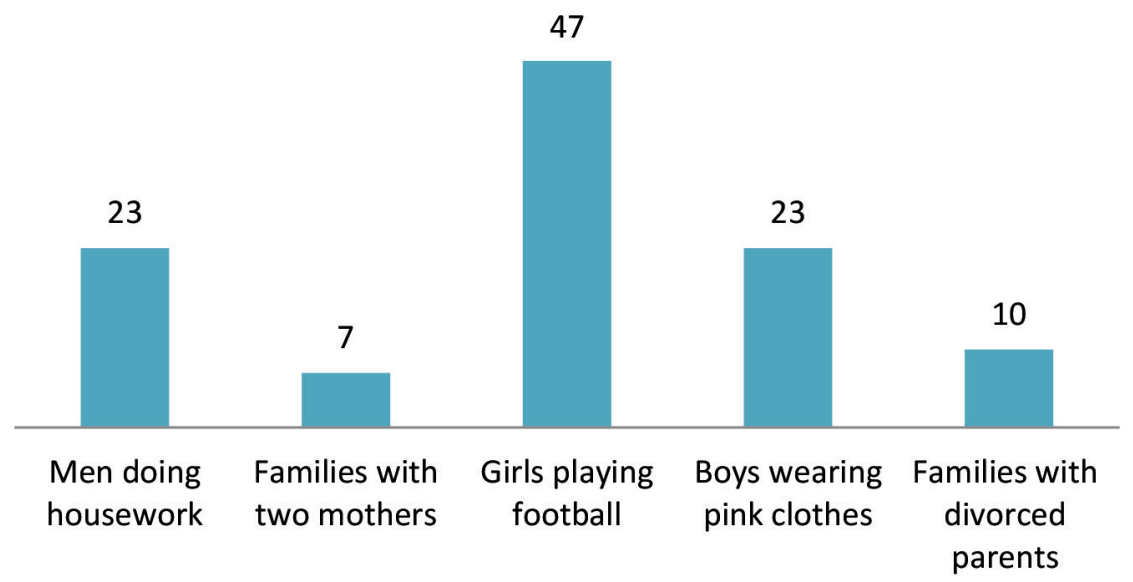

Figure 15. Frequency of the images marked by the students.

When the students were asked to select the images that usually appear in their English textbooks, the chosen images coincided with the ones that show role models that are more socially accepted in our culture - girls playing sports that are usually stereotypical for boys, men doing housework and boys wearing pink -, while the elements that are less accepted in our society, like homo-parental families, have less visibility. 
Also, the results demonstrate that only $6 \%$ of the students had talked in the English classroom about gender roles; however, the 34 per cent of the students would be interested in talking about this topic. Finally, the students were asked to answer a riddle that appears in Basow's book Gender Stereotypes and Roles (1992) in order to analyse if they have stereotypical views regarding jobs. The results show that the students associated the profession of surgeon to a man in $64 \%$ of the answers, even though the most straightforward answer would be that if the father has died, the doctor should be the mother. Nevertheless, there is a positive aspect to underline: some of the answers to this question show that five of the students had a non-stereotypical idea of the family and the gender roles within this institution because they considered that the characters represented in the riddle could belong to a homoparental family.

\section{Conclusion}

Drawing on all the data exposed, it can be concluded that the main initial objectives have been achieved. To begin with, the teacher's surveys show that the teachers have a relevant lack of training regarding gender stereotypes, which makes them vulnerable to not being critical when choosing the teaching materials and to unconsciously promote a stereotypical view of gender in their lessons. In the second place, it can be concluded that the three books analysed, in greater or lesser degree, contain gender stereotypes and women have less visibility at the graphic and linguistic levels. Furthermore, there is no visibility of family and sexual orientation diversity; an aspect that may transmit hetero-patriarchal models. Finally, the Students' surveys have demonstrated that some of the students have strong gender schema, especially about women's, roles and personality traits what justifies the importance of carrying out analyses of the textbooks.

Yet, despite the evidences just shown, it would be arbitrary to conclude that there is a univocal influence of the English textbooks in the formation of gender stereotypes, because many factors intervene in the formation of gender stereotypes, such as the children's family ideology, the rural environment where students come from and the teachers' attitude towards gender and stereotypes. Furthermore, the analysis has been applied to three textbooks most used according to the teachers' survey. But these textbooks, in some cases, did not coincide with the textbook that some students were using so they might be influenced by didactic material that has not been analysed yet. Moreover, it is also essential to consider that these children are in the last year of Primary School and, therefore, they have been influenced by many different modalities of textbooks along their school years.

With regard to the three textbooks analysed, we consider that none of the textbooks is suitable to teach gender awareness in the English classroom because all of them contain gender stereotypes. This makes the textbook a tool in which inequality and patriarchal values are transmitted to the students. However, all these textbooks could be used if the teachers were aware of the values transmitted and so they used them as modifiable and interactive materials in which this stereotypical content can be the origin of debates or is replaced by content promoting egalitarian values. For instance, the teacher can change the gender and roles of the characters if they are stereotypical or create new ones, design extra activities that include different types of families and talk about people who hold non-traditional occupations, highlight the 
relevance of female personalities, alternate the order of the male and feminine pronouns when explain in the blackboard, and so forth. With this purpose in mind, teachers can also use the checklists developed for the analyses of these books as a tool to evaluate the sexist content of the teaching materials that they are currently using in their English classrooms. At the same time, the checklists, the guidelines and the analysis presented in this study can become tools for the creation of new materials.

To conclude, we should bear in mind that the reality uncovered by this study is sometimes invisible for students, teachers, families, and for the whole society because stereotypes can be easily unperceived and they have permeated all the layers of the social structures. This may explain why some of the actions proposed are not usually carried out in our educational institutions. Thus, the relevance of this study lies on the fact that it highlights two realities: the stereotyped content of the textbooks and the stereotyped gender schemas of some the students of $6^{\text {th }}$ grade of Primary School, which seem invisible for the educative community. This study can thus be the basis for developing some measures to avoid gender stereotypes in teaching materials. Further investigation about this topic should focus on the analyses of films, songs and reading books used in the English classroom. And the most ambitious but necessary future aim will have to do with the analyses of the teaching materials of all the subjects taught in Primary School, as this issue should be studied from an interdisciplinary perspective. Therefore, we hope this study contributes to achieving an egalitarian society where no more invisible truths blind the eyes of our future generations.

\section{References}

Ayala, Ana. I y Pilar L. Mateo (1999). Educar en Relación:esterotipos y conflictos de género. Zaragoza: Gobierno de Aragón Departamento de Educación y Ciencia.

Basow, Susan (1992). Gender Stereotypes and Roles. Third Edition. Belmont, California: Brooks/Cole Publishing Company.

Boletín Oficial de Aragón (2007). Orden de 9 de mayo de 2007, del Departamento de Educación, Cultura y Deporte, por la que se aprueba el currículo de la Educación primaria y se autoriza su aplicación en los centros docentes de la Comunidad autónoma de Aragón. 1 de Junio de 2007, núm.65 [Consultado el 22 de Mayo de 2016].

Boletín Oficial del Estado (2014). Real Decreto 126/2014, de 28 de febrero, por el que se establece el currículo básico de la Educación Primaria. 1 de Marzo de 2014, núm.52, pp.19349-19420. [Consultado en 22 de Mayo de 2016].

Bottemore, T. (1976). "Foreword". Reproduction in education, society and culture. Ed. P. B.C. Passeron. London: Sage Publications, xv-xvii.

Bourdieu, Pierre, \& Jean C. Passeron (1990) Reproduction in Education, Society and Culture. London: Sage Publications.

Butler, Judith (1990). Gender Trouble: Judith Butler Feminism and the Subversion of Identity. New York and London: Routledge.

Butler, Judith (2004). Undoing Gender. New York and London: Routledge.

Casey, Helen and PaulShipton (2015). Oxford Rooftops. Oxford: Oxford University Press.

CIDE and Instituto de la mujer (2004). Mujeres en cargos de representación del Sistema Educativo. Madrid: Instituto de la Mujer.

CNIIE and Instituto de la mujer (2011). Mujeres en cargos de representación del Sistema Educativo II. Madrid: Instituto de la Mujer. 
Dai, Lili (2011). Practical Techniques for Cultural-based Language. Journal of Language Teaching and Research 2.5:1031-1036.

Dominguez, Liliana. M (2003). Gender Text Book Evaluation. Birmingham: University of Birmingham.

Harmer, Jeremy (2015). The Practice of English Language Teaching. Harlow: Pearson.

Hymes, Dell H (1973). On communicative competence. In Pride, J. B. and Holmes, J., eds. Sociolinguistics. Selected Readings. Harmondsworth: Penguin, 269-293.

Kalayci, Nurdan and Fahriye Hayirsever (2014). Analysis of Citizenship and Democracy Education Text Book in the Context of Gender Equality and Determining Student's perceptions on Gender Equality. Educational Sciences:Theory \& Practice 14: 1065-1072.

Karniol, Rachel (2011). The Color of Children's Gender Stereotypes. Spring Science \& Bussiness Media LLC: 119-132.

Kin-Moon, Ban (2016). Introductory Statement. STEP IT UP: Global Leaders'Meeting on Gender Equality and Women's Empowerment. Ed. UN Women New York: UN Women Headquarters, 16-24.

Kumaravadivelu, B (2006). TESOL Methods: Changing Tracks, Challenging Trends. TESOL Quarterly 40: 59-81.

Lyons, Anthony and Yohishisa Kashima (2001). The reproduction of the culture: communication processes tend to maintain cultural stereotypes. Social Cognition 19.3: 372-394.

Mohamed, Emma (2012). Quest 6. Oxford: Macmillan.

Nunan, David (2004). Task-Based Language Teaching. Cambridge: Cambridge University Press.

Ortner, Sherry (1974). Is Female to Male as Nature is to Culture? In Rosaldo, Michelle Z. and Lamphere, Louise, eds. Women, Culture and Society. Standford, CA: Standford University Press, 68-87.

Peiró Velert, C. (2001) Materiales curriculares y formación de profesorado en educación física. Tandem 4: 19-33.

Phillips, Ruth and Viviene E. Cree (2014). What does the 'Fourth Wave' Mean for Teaching Feminism in Twenty-First Century Social Work? Social Work Education 33: 930-943.

Phillips, Sarah and Paul Shipton (2015). Great Explorers. Oxford: Oxford University Press.

Porreca, Karen L (1984). Sexism in Current ESL Textbooks. TESOL Quarterly 18.4: 705724.

Richards, Jack. C (2006). Communicative Language Teaching Today. New York: Cambridge University Press.

Saewyc, Elisabeth M (2011). Research on Adolescent Sexual Orientation: Development, Health Disparities, Stigma, and Resilience. Journal of Research on Adolescence 21.1: 256-272.

Siniscalco, María T. and Nadia Auriat (2005). Quantitative research methods in educational planning. Module 8 Questionaire Design. Paris: International Institute for Educational Planning/ UNESCO.

Snyder, R. Claire (2008). What Is Third-Wave Feminism? A New Directions Essay. Signs: Journal of Women in Culture and Society 34.1: 175-196.

Sowden, Colin (2007). Culture and the "good teacher" in the English Language Classroom. ELT Journal 61.4: 304-310.

Sunderland, Jane (1992). Gender in the EFL Classroom. ELT Journal 46.1.1: 81-91.

Sunderland, Jane; Maire Cowley; Fauziah Abdul Rahim; Christina Leontzakou and Julie Shattuk (2002). From Representation towards Discursive Practices: Gender in the Foreign Language Textbook Revisited. In Litosseliti, Lia and Jane Sunderland, eds. Gender 
Identity and Discourse Analysis. Amsterdam/Philadelphia: John Benjamins Publishing Company, 223-256.

Terrón, María. T. and Verónica Cobano-Delgado (2008). El papel de la mujer en las ilustraciones de los libros de texto de educación primaria. Foro de Educación 10: 385-400.

Tran-Hoang-Thu (2010). Teaching Culture in the EFL/ESL Classroom. San Diego: Alliant International University.

United Nations (1948). The Universal Declaration of Human Rights. Paris: General Assembly Resolution 217A. 
